\title{
HOMOSSEXUALIDADE, TESTEMUNHO E CÁRCERE: PENSAR O EU, PENSAR O OUTRO
}

\author{
Guido Vieira Arosa ${ }^{1}$ \\ João Camillo Penna ${ }^{2}$
}

RESUMO: O artigo abordará a relação do homossexual com o cárcere, partindo do modo pelo qual o heteronormativo se posicionou diante desse homossexual encarcerado. Tendo por base dois livros canônicos da literatura de testemunho dos sobreviventes da Segunda Guerra, que focalizam o preso político e o preso por motivos religiosos, É isto um homem?, do italiano Primo Levi e A espécie humana, do francês Robert Antelme, se analisará o posicionamento desses autores frente a homossexualidade observada por eles de longe, no campo de concentração-extermínio. Por sua vez, vêm à tona os testemunhos Antes que anoiteça, do escritor cubano e homossexual Reinaldo Arenas, e do francês homossexual Pierre Seel, Eu, Pierre Seel, deportado homossexual, ambos enviados a presídio e campo de concentração-extermínio. Se objetiva, portanto, analisar as diferentes abordagens do outro e do eu.

Palavras-chave: Homossexualidade; cárcere; silêncio; testemunho; memória.

Abstract: The paper approaches the homosexual relationship with its jail, starting by the way in which the heteronormativity stood before this incarcerated homosexual. Based on two canonical books of the testimony literature of the survivors of World War Two, which focus on the political prisoner and the prisoner for religious reasons, If this is a man, from the Italian Primo Levi, and The human race, by the French Robert Antelme, it analyzes the position of these authors against the homosexuality observed by them from the outside, in the concentration-extermination camp. On the other hand, comes out the testimonies Before night falls, by the Cuban and homosexual writer Reinaldo Arenas, and by the French homosexual Pierre Seel, I, Pierre Seel, deported homosexual, both sent to prison and concentration-extermination camp. The speech aims to analyze the different approaches of the other and of the self.

Keywords: Homossexuality; prison; silence; testimony; memory.

\footnotetext{
1 Mestrando em Teoria Literária pelo Programa de Pós-graduação em Ciência da Literatura da Faculdade de Letras da UFRJ. E-mail: guidovieiraarosa@gmail.com

2 Professor pós-doutor associado do Departamento de Ciência da Literatura da Faculdade de Letras da Universidade Federal do Rio de Janeiro. E-mail: jcamillopenna@gmail.com
} 
"Eu antes tinha querido ser os outros para conhecer o que não era eu. Entendi então que eu já tinha sido os outros e isso era fácil. Minha experiência maior seria ser o outro dos outros: e o outro dos outros era eu." Clarice Lispector

\section{MEMÓRIA DO EU (OU DO OUTRO?)}

Primo Levi, escritor mais analisado pelos teóricos do testemunho da Shoah, sugere, em $E$ É isto um homem?, publicado em 1947, que "os homossexuais jovens e atraentes", por conta de uma "seleção natural" (LEVI, 1988, p.90), restaram sobreviventes a 1944, em Auschwitz. $\mathrm{O}$ autor, judeu e antifascista, enviado ao campo por sua filiação religiosa, considerou que homossexuais não morreram porque se aproveitaram ardilosamente de suas sexualidades. No entanto, no começo do livro, quando fala dos "hóspedes do Campo", cita apenas "os criminosos (que) levam, ao lado do número, costurado no casaco, um triângulo verde; os políticos, (que levam) um triângulo vermelho; (e) os judeus, que formam a grande maioria, (que) levam a Estrela de David, vermelha e amarela" (Ibidem, p.31). Ou seja, os homossexuais não fazem parte da comunidade do campo, ainda que citados para ressaltar que dele se safaram por meio de artimanhas. Levi não volta a citar em seus outros livros os que receberam em seus uniformes o triângulo rosa e que morreram assassinados em massa durante a guerra, e que precisaram, após o fim do conflito, manter silêncio quanto a suas condições sexuais, vide que ser homossexual se mantinha como uma pecha perigosa e vergonhosa.

Pier Paolo Pasolini, contemporâneo do também italiano Primo Levi, assumidamente homossexual e por isso assassinado, em 1975, em uma praia, afirmou o seguinte, em texto dos anos 1970, cujo título é direto, Discurso sobre os tabus que precisam ser "quebrados a qualquer custo", ao comentar citação do livro Gli omosessuali (Os homossexuais, em português), dos especialistas franceses M. Daniel e A. Baudry, escrito quando ainda era ínfimo o estudo sobre os homossexuais deportados e assassinados:

"É significativo a esse propósito que Hitler tenha mandado para os campos de concentração três grupos de minorias, com o mesmo pretexto de salvaguarda da defesa da raça: os judeus, os ciganos e os homossexuais. (Os homossexuais, diferenciados por um triângulo rosa, eram submetidos a tratamentos particularmente abomináveis. São entretanto os únicos que, depois da guerra, nunca tiveram direito a uma indenização.)" Inclusive - podemos acrescentar - são os únicos para quem as coisas continuam essencialmente como antes, sem o menor sinal de uma forma qualquer de ressarcimento (PASOLINI, 1990, p.162).

Já o pesquisador francês Michael Pollak, que escreveu o livro Os homossexuais e a Aids, publicado na França em 1988, mas ainda hoje muito importante para a compreensão do significado do testemunho da Aids para o homossexual, afirma, em artigo sobre o silêncio e o esquecimento no contexto da memória, que 
pesquisa de história oral feita na Alemanha junto aos sobreviventes homossexuais dos campos comprova tragicamente o silêncio coletivo daqueles que, depois da guerra, muitas vezes temeram que a revelação das razões de seu internamento pudesse provocar denúncia, perda de emprego ou revogação de um contrato de locação. Compreende-se por que certas vítimas da máquina de repressão do Estado-SS - os criminosos, as prostitutas, os 'associais', os vagabundos, os ciganos e os homossexuais - tenham sido conscientemente evitados na maioria das memórias 'enquadradas' e não tenham praticamente tido voz na historiografia (POLLAK, 1989, p.12-13).

A afirmação anterior é corroborada por declaração à revista gay europeia Gai Pied, em 1980 (declaração feita ao, dentre outros, jornalista Jean Le Bitoux, que ajudou Pierre Seel a publicar seu livro), de Jean-Paul Sartre, que se justifica pelo silêncio de grande parte da academia, ele mesmo fazendo parte desse silêncio, em relação à deportação, prisão e genocídio de homossexuais durante a Segunda Guerra:

Por que não existe uma palavra em seus escritos políticos sobre o extermínio de homossexuais por Stálin e Hitler? - É porque eu não sabia sobre esse tipo de massacre, se eram sistemáticos e quantas pessoas haviam afetado. Eu não tinha certeza. Os historiadores falam pouco sobre isso. Eu podia criticar muitas coisas desses ditadores, mas sobre isso não podia criticá-los, pois eu não sabia. (SARTRE apud SEEL, 2012, p.168)

Robert Antelme, um dos principais presos políticos franceses da Segunda Guerra, relata em seu testemunho A espécie humana, também publicado em 1947, em trecho de sete páginas, o caso de Félix e X. Félix, um preso francês, que conseguiu mais comida que os demais por dar aos algozes o ouro que eram seus dentes, é descrito como alguém que aprendeu rápido a engrenagem do campo e por isso tinha coxas mais grossas que os demais, escondia batatas em seu travesseiro, e se insinuava aos outros ao dormir apenas com uma camisa, que escondia e revelava seu pênis: "Às vezes passava as duas mãos no sexo e olhava ao redor. O pequeno X. dormia não longe de Félix. Quando se expunha assim, exibindo as pernas e as acariciando, era, sobretudo, na direção de X. que lançava olhares" (ANTELME, 2013, p.208). Já o prisioneiro X, também francês, é descrito como um ser sem autonomia, moreno e pequeno, faminto, sujo e ferido, sugado pela opressão do campo, sem vontade própria e que sempre, segundo Antelme, observava com a nesga dos olhos o corpo de Félix a se insinuar. Em ambientes de encarceramento, onde apenas o masculino prevalece e o desejo sexual é reprimido, é típica a descrição da cena em que um preso mais forte exerce poder sobre o mais fraco, para obtenção de uma válvula de escape ao gozo em troca de algum benefício mínimo ao mais fraco, como alimento. Deste modo, o autor relata, revelando a ambiguidade de Félix, que protege o mais fraco, mas também o oprime:

X., que morria de fome e estava muito debilitado, tinha reparado no pão e nas batatas de Félix, que, por sua vez, havia reparado em X. (...) Félix deu batata ao 
pequeno e acariciou-lhe o pescoço sujo. (...) deu-lhe mais uma batata com a outra mão. (...) disse que, quando tivesse fome, bastava procurá-lo. (...) Félix o puxou contra si, mas ele resistia. Félix dizia entre os dentes: “Eu lhe darei de comer!" Não queria, mas Félix repetia: "Você não quer comer, não quer comer?" O pequeno não contestava. Félix o mantinha bem apertado (Ibidem, p.208-209).

No dia seguinte, um preso comum francês denuncia ambos a Paul, que contou aos SS. Mas Paul, segundo Antelme, em sentença aqui a se refletir, "dormia com o antigo Stubendienst (atendimento de quarto, em tradução literal) francês" (Ibidem, p.209). Por conta disso, X. e Félix são violentados por seus superiores. X. recebe a tortura de forma silenciosa: é arrastado até o centro do campo, jogado e, com suas nádegas à mostra, chicoteado diversas vezes na região, até perder a consciência e ser levado, desmaiado, por dois colegas até seu dormitório. Ele recebe calado a violência, como também se manteve calado diante da oferta de alimento mediante ato sexual. Já Félix, ao ser pego para receber jatos de água fria direto em seu coração, reage com diversos xingamentos, mas não morre por conta desses jatos, porque conseguia se alimentar e se mantinha forte, diferente de X. Em seguida, sob chutes e socos, o obrigam a carregar pedras. Alquebrado, conseguiu sobreviver a tudo, e no fim, já em seu dormitório, um companheiro ainda "estendeu-lhe a mão" (Ibidem, p.212). Mas diz Antelme, sobre a impressão que os demais prisioneiros tinham de Félix e X.:

Os golpes que os sujeitos recebiam confirmavam em definitivo a consciência (para os que não apanhavam) de estar do lado certo. Não se pode apanhar e ter razão; ser sujo, comer restos, e ter razão. (...) Alimentado, Félix não morria sob o jato. $\mathrm{Nu}$, não era um esqueleto. Tivera forças para violentar o garoto, o que agora lhe custava a ducha. (...) De manhã, tínhamos dito que Félix era um filho da puta por se aproveitar do garoto morto de fome. Era nojento. Era sórdido (Ibidem, p.210-211).

Um, por ter comida, rebaixou o outro a "paciente" de seu sexo, e com isso acabou também rebaixado; o outro, para ter comida, se rebaixou ao outro como "paciente" do sexo dele, e com isso acabou ainda mais rebaixado. Me pergunto, será que sobreviveram ao campo?

Desde É isto um homem?, onde o homossexual não é citado como parte de um grupo de vítimas do campo de extermínio-concentração, e mencionado apenas de forma no mínimo irônica, ao se ler que homossexuais belos e jovens se mantiveram de pé (ou seja, se utilizaram e se aproveitaram de seus corpos como moeda de troca), até A espécie humana, onde não se pode falar necessariamente em homossexualidades, mas sim em corpos masculinos, que pela necessidade de sobrevivência e de gozo, pelo dever de obediência do mais fraco e pelo imperativo de mando do mais forte, se subjugam e se sobrepõem ao outro, sofrendo das consequências de seus atos em silêncio, sem reação, em X., e xingando, reagindo, em Félix. Livros esses, É isto um homem? e A espécie humana, escritos escritos nos diretos anos pósguerra por autores que observaram a homossexualidade de fora, de modo mais ou menos consciencioso. Mas como pensar o cárcere, o gozo em cárcere e o assassínio promovido pela moral, no texto do homossexual que se escreve enquanto homossexual? Da invisibilidade ao 
protagonismo da cena. Tentemos, então, compreender o modo com o qual dois homossexuais, Pierre Seel e Reinaldo Arenas, vítimas dos encarceramentos tanto da Segunda Guerra Mundial como dos sistemas autoritários latinoamericanos, respectivamente, relataram as experiências que os dois autores heterossexuais anteriormente citados tentaram, ou não, trazer à luz: a do cárcere, a do sexo em cárcere, a do aniquilamento em cárcere. Do cânone (Primo Levi, Robert Antelme), ao contra-cânone (Pierre Seel, Reinaldo Arenas).

\section{MEMÓRIA DO OUTRO (OU DO EU?)}

Reinaldo Arenas, escritor cubano que, por ser homossexual e discordar da repressão política do regime de Fidel Castro dos anos 1960 e 1970, fazendo em seu texto transparecer tanto sua sexualidade como seu posicionamento "antirrevolucionário", teve seus livros censurados na ilha e, entre 1974 e 1976, ficou preso em El Morro e na sede principal da Segurança de Estado cubana, Villa Marista, se exilando nos Estados Unidos em 1980, até seu suicídio, em 1990, por conta da Aids. O autor, que mantém em todas as suas narrativas uma tensão erótica homossexual palpitante, em seu testemunho Antes que anoiteça, finalizado em 1990 e publicado pela primeira vez em 1992, relata seu período de prisão de modo cruel e aberto, revelando a forma como o homossexual necessita se portar atrás das grades, em um paralelo interessante ao que acabamos de ver em Antelme.

Segundo Arenas, preso estava com sua vida sexual e, portanto, sua liberdade enquanto ser humano, absolutamente comprometida, vide que "recusava as propostas eróticas dos presos". Ele afirma que

não era a mesma coisa fazer amor com alguém livre e fazê-lo com um corpo escravizado atrás de uma grade, que talvez me escolhesse como objeto erótico porque não existia nada melhor a seu alcance, ou porque, simplesmente, estava morrendo de tédio. (...) Não havia nenhuma grandeza naquele ato, teria sido rebaixar-me. (...) Na prisão, as relações sexuais transformam-se em algo sórdido que se realiza sob o signo da submissão e do desdém, da chantagem e da violência (...) O belo na relação sexual está na espontaneidade da conquista (...) $\mathrm{Na}$ cadeia, tudo é óbvio e mesquinho; o próprio sistema carcerário faz com que o preso se sinta como um animal, e qualquer forma de sexo é sempre algo humilhante (ARENAS, 2009, p.220).

Apesar de não serem discernidos com cores distintas em seus uniformes, em El Morro os homossexuais deveriam ocupar galerias específicas, não sendo misturados aos demais presidiários, e tais galerias eram localizadas no subterrâneo do presídio, que inundava sempre que a maré subia, local sem banheiro e circulação de ar, mantido por soldados que estavam lá porque haviam recebido algum tipo de punição. "A galeria das bichas-loucas era realmente o último círculo do inferno; é preciso lembrar que muitos daqueles homossexuais eram criaturas destroçadas que a discriminação e a miséria transformaram em criminosos comuns" (Ibidem, p.222). A relação da "bicha-louca" com a cadeia é dissecada por Arenas, 
que relata casos de suicídio; de presidiários que por "machismo" escravizavam seus parceiros sexuais, eles servindo até para ficarem de prontidão afastando as moscas do rosto de seus donos; casos de heterossexuais estuprados em suas celas que precisavam se "confessar" homossexuais para irem à galeria subterrânea e sofrerem menos violência etc. Arenas, que optara por não se relacionar dentro do presídio, vide que "o amor é algo livre e a cadeia é algo monstruoso" (Ibidem, p.229), acaba direcionando sua libido à escrita, após descobrirem ser ele um escritor, se tornando então "o namorado ou o marido literário de todos os presos de El Morro", ao redigir as cartas que os encarcerados desejavam enviar às suas famílias. No entanto, segundo Margarita Camacho, é neste momento que cessam, ou quem sabe são impedidas de se fazer chegar, as próprias cartas do autor ao casal de amigos Jorge e Margarita Camacho, que viviam na Europa e eram sua válvula de escape para suas obras enviadas clandestinamente ao exterior (CAMACHO In ARENAS, 2010, p.17).

No entanto, antes de El Morro, Arenas já havia sido preso, no verão cubano de 1973, após, junto de um amigo, fazer sexo com alguns jovens em meio aos manguezais na praia de Guanabo. Em situação semelhante à relatada por Pierre Seel - fichado na delegacia como "homossexual" e enviado à campo de concentração após denunciar à polícia que um relógio seu havia sido furtado em uma praça onde havia encontros gays, o que revela a distância e confronto moral que há entre o homossexual e a polícia -, tais jovens, após o sexo, roubaram os pertences de Arenas e do amigo, o que fez com que este buscasse a polícia para fazer uma denúncia. Apesar de o roubo ter se mostrado evidente, vide que os jovens foram flagrados com os pertences do escritor, eles afirmaram: "São veados que tentaram nos seduzir" (Ibidem, p.193). Como Arenas e o amigo eram notoriamente homossexuais e um dos rapazes tinha um parente na delegacia de Guanabo, o escritor acabou preso, sendo depois acusado de ser corruptor de menores pela imprensa, no que se configura pela situação onde a vítima é colocada na situação de e acaba se vendo como o próprio algoz: "Assim, passamos de acusadores a acusados e ficamos presos" (Ibidem, p.193).

Apesar de acreditar não haver provas contra ele, Arenas não contava, à época, com a seguinte lei: "Mas não me lembrei de um artigo da lei castrista que diz que se um homossexual cometer um delito erótico, basta a denúncia de uma pessoa para que seja preso. E, além de ficarmos detidos, ainda abriram processo contra nós" (Ibidem, Idem). Solto sob fiança conseguida por um amigo, a UNEAC - instituição na qual o escritor ainda fazia então parte, vide que depois do episódio ele acabou sendo retirado da lista oficial de escritores de Cuba - foi chamada à delegacia e destacou sobre Arenas, realizando posteriormente um dossiê contra ele: "não passava de um contrarrevolucionário homossexual, que publicara livros no exterior" (Ibidem, Idem). Com o prosseguimento do processo e a certeza de condenação, Arenas intensificou suas investidas em sair clandestinamente do país, mas a polícia foi mais rápida e, no que sugere o autor, a partir de denúncia de sua própria tia, com quem vivia, a polícia o encontrou e o enviou à delegacia de Miramar, de onde acabou conseguindo fugir, sem então saber que ainda seria enviado para El Morro: "Achava que minha situação chegara ao limite; no entanto, se existe algo que um sistema totalitário pode nos ensinar, é que as desgraças são infinitas" (Ibidem, p.192).

Além do presídio como cárcere ao homossexual contrarrevolucionário em Cuba, houve as UMAPs (Unidades Militares de Ajuda à Produção), campos de trabalho que existiram 
na província de Camagüay entre 1965 e 1968, fechados após protestos de violação dos direitos humanos. Com o objetivo de "reabilitação" de páreas sociais, tais campos passaram a receber homossexuais, membros de religiões como as testemunhas de Jeová, e dissidentes políticos de forma geral. O lema dessas unidades era "O trabalho faz o homem", que pode em associação livre remeter a "O trabalho liberta", de Auschwitz. Em entrevista ao documentário Conducta impropria (ALMENDROS; LEAL, 1984), o poeta cubano Heberto Padilla, exilado da ilha desde 1979, afirma que as UMAPs tiveram início a partir de uma viagem de Raul Castro à Bulgária, país aliado da União Soviética. Raul teria, segundo Padilla, percebido que as ruas búlgaras estavam limpas de "elementos antissociais", em contraste às ruas cubanas, povoadas por homossexuais escandalosos, em situação que o preocupava. Disseram a ele, então, que havia um campo à parte, onde enviavam tais elementos, sobretudo os homossexuais.

Padilla fora preso, em 1971, após o "atrevimento" de apresentar, para um concurso cultural oficial, um livro crítico ao sistema, Fuera del juego, em um momento em que já era conhecido internacionalmente. Para compreender, então, os anos 1970 como uma década em que o aparelhamento sociocultural de estado foi ferrenho, tem-se que, também em 1971, ocorria em Havana o I Congresso de Educação e Cultura, que perseguiu os homossexuais, apesar de as UMAPs oficialmente já não existirem. Como afirma Arenas:

A mais violenta perseguição daquele congresso foi dirigida contra os homossexuais. Foram lidos textos rotulando o homossexualismo como um caso patológico e, mais importante, dizia-se que todo homossexual ocupando um cargo em órgãos culturais seria imediatamente exonerado. Teve início a chamada parametraje, isto é, cada escritor, cada artista, cada dramaturgo homossexual recebia um telegrama informando-o de que não reunia os parâmetros políticos e morais para o bom desempenho do cargo que ocupava e, portanto, perdia seu emprego e tinha que ir para um campo de trabalhos forçados, onde executaria outra tarefa. (Ibidem, p.175)

Sendo assim, apesar de Arenas ter sido "poupado" de ser confinado em uma UMAP (OLIVARES, 2013, p.174), a partir de 1969 o governo passou a tornar obrigatório o comparecimento mediante convocação para o trabalho nos campos de cana-de-açúcar, para abastecimento da população e alcance de metas de colheita estipuladas pelo Estado e alardeadas pela propaganda oficial. O trabalho ainda era feito sob condições precárias e, como se pôde ver acima, se mantinha no país o intuito de encarceramento do homossexual. Apesar de a UNEAC, órgão oficial dos escritores e artistas cubanos, ter protestado à época contra a existência das UMAPs, houve, por ela, incentivo para que seus membros fossem enviados ao trabalho forçado: "Na UNEAC havia constantes assembleias para nos obrigar a participar da colheita e, por fim, a entidade 'decidiu' fechar e mandar todos os escritores aos engenhos de açúcar para cortar cana” (ARENAS, 2009, p.161). Arenas se mantém trabalhando nestes campos até 1973, um ano antes de ser enviado preso a El Morro.

Segundo o escritor, foi estratégia do governo tornar o alistamento militar obrigatório em tempos de paz, apenas para abastecer os campos de cana com mão de obra: "Abandonar 
aquelas plantações podia representar, para qualquer um dos rapazes, de cinco a trinta anos de cadeia" (ARENAS, 2009, p.164), segundo Arenas. O autor destaca a impossibilidade de o outro, o leitor, compreender o que significava o confinamento em alojamentos subumanos e o trabalho forçado com a cana-de-açúcar debaixo do sol à pino de meio-dia, "Para quem não passou por isso, não é possível compreender o que significa” (Ibidem, Idem), mas afirma que ter passado por essa situação fez com que ele pudesse compreender a experiência do outro, que é dele ao mesmo tempo próxima e afastada: "podíamos entender por que os índios preferiam o suicídio a continuar trabalhando como escravos; entender por que tantos negros tiravam a própria vida asfixiando-se. Agora eu era esse índio, eu era o negro escravo" (Ibidem, Idem). Do mesmo modo, por mais que impossível ao outro compreender, é para o autor obrigatório relatar, no double bind citado no primeiro capítulo da dissertação: “A visão de tanta juventude escravizada foi o que inspirou meu poema 'El central'. Lá mesmo redigi essas páginas; não podia permanecer como testemunha silenciosa de tanto horror" (Ibidem, Idem). E o autor finaliza sua fala sobre as plantações de cana-de-açúcar ao afirmar que, após ser libertado, passou por um Carnaval regado de divertimentos e aventuras sexuais, vide que: "A luxúria, depois de tanta repressão, manifestou-se de forma brutal; os banheiros eram enormes centros de fornicação; em meio ao cheiro de urina, todo mundo chupava e transava" (Ibidem, p.170).

Por sua vez, Pierre Seel, homossexual francês e cristão da região da Alsácia, incorporada à Alemanha durante a ocupação nazista, foi encarcerado em 1941, aos 18 anos, no campo de Schirmeck, e liberado após seis meses de confinamento, tendo que, em seguida, servir ao exército nazista, por ser considerado então um alemão. Seel, em Eu, Pierre Seel, deportado homossexual, publicado em 1994, corporifica, no caso aqui estudado, o silêncio ao homossexual de sua condição de deportado, mesmo após a guerra; do mesmo modo, vivifica as atrocidades contra o homossexual sofridas em campo de concentração e extermínio, que vão de encontro ao gesto, que se diga, pouco profundo, na análise de Primo Levi no que diz respeito ao homossexual vítima.

Seel, que foi liberado relativamente rápido do campo porque deveria ainda lutar pela Alemanha na guerra, afirma que, ao ser liberado de Schirmeck, esteve diante de um comandante, que ressaltou:

\footnotetext{
"Ouça-nos bem, se você ficar tentado a dizer seja o que for sobre o que você viveu no campo, se você decepcionar as autoridades do Reich, evidentemente não demorará a voltar para dentro dessas cercas". De modo calmo, mas muito firme, exigia o meu mutismo total. Eu estava atônito; não entendia nada. Mas obedeci e assinei (documento de libertação) sem ler (SELL, 2012, p.60).
}

Esse "não contar" se insere na lógica do algoz que destrói, na vítima, sua realidade do que foi vivenciado no campo, fazendo com que a impeça de testemunhar, transformando o evento-campo em um evento circunscrito a grandes silêncios e dificuldades de assimilações com o real. Mas também, no contexto aqui analisado, remetido aqui a Pasolini e Pollak, esse silêncio é tido no fato de que mesmo após o fim da guerra, ser homossexual se mantinha uma pecha social e um motivo para ainda assim manter presos cidadãos. Por isso, Seel não conseguiu contar à sua família o vivenciado no campo. Diferente, por exemplo, de prisio- 
neiros judeus, que tinham na família uma possibilidade de escuta, o homossexual se viu em uma ilha:

E desde que eu a havia deixado, minha família havia se informado de que eu era um Schweinhund (cachorro asqueroso, viado imundo, segundo o próprio Seel). Católicos e preocupados com a sua boa reputação, como os meus pais iriam reagir? Iriam eles me receber ou não? E como? Mas o que explicar a eles, como me explicar, já que eu estava obrigado a permanecer em silêncio? (Ibidem, p.62).

Seel chega à sua casa e é recebido pela família à mesa, jantando (lembra o sonho de Primo Levi, relatados em A trégua e Os afogados e os sobreviventes, o de estar em uma mesa cheia de familiares, contando sua história do campo, e ninguém ouvindo, todos se levantando). Diz Seel: "Meu pai se levantou da mesa. (...) 'Sente-se conosco à mesa. Não falemos mais nada sobre isso (...)’ Ninguém quebrou o silêncio” (Ibidem, p.62-63). Seel se questiona e martiriza, afirmando que ninguém de sua família fez perguntas naturais a um retornado do horror, sobre o que ele havia passado, se ele era de fato um homossexual, por que o haviam libertado. "Mas se alguém tivesse perguntado, eu não teria respondido: eu estava preso ao meu duplo segredo. E a esses olhares silenciosos, levei quarenta anos para responder" (Ibidem, p.63).

Dentro do campo de concentração, Seel precisou reprimir seu desejo para não morrer, o que lembra o relato de Arenas, do mesmo modo que fora do campo também o fez, quando adentrou uma vida heteronormativa para se esquecer da lembrança das atrocidades vividas confinado. Ele diz que, no campo, "entre pausas do trabalho, (...) me fechava em uma solidão desesperada pela qual não passava nenhum desejo sexual. A própria ideia de desejo não tinha lugar nenhum nesse espaço. Um fantasma não possui nem fantasia, nem sexualidade" (Ibidem, Idem). No que lembra X. de Antelme, Seel afirma ter sido "reduzido ao estado de observador mudo" (Ibidem, Idem).

Sendo assim, Seel tinha um namorado, enviado ao mesmo campo, que logo nas primeiras semanas de prisão foi comido vivo por cães, diante de seus olhos, mas não se focalizará essa parte, descrita no livro em pormenores, pois basta que saibamos que "não me esquecerei jamais desse assassinato brutal do meu amor" (Ibidem, p.58). Dito isso, e tendo em vista que Seel, após o campo, viveu mais de quarenta anos uma vida heteronormativa, se mantendo no grande e aterrador silêncio, encontrando apenas nos anos 1980 terreno fértil para relembrar, voltando totalmente ao campo, já idoso, sendo o primeiro deportado homossexual francês a testemunhar em livro, a 1994, para dizer que ele se mantém vivo por uma vela que arde todos os dias em sua cozinha em memória de Jo, seu amor morto no campo, em 1941. Ou seja, o livro de um homem que reprimiu ao longo da vida seu desejo existe tendo como base seu amor morto, há tantos anos. A vela que Seel faz viver, todas as noites, em memória de Jo, seu amor morto, pode parecer ínfima e fugaz, mas está carregada de potência, dor e memória, e revela toda sua força quando se percebe que, segundo Didi -Huberman em seu manifesto sobre a sobrevivência dos pequenos vaga-lumes mediante as atrocidades do contemporâneo: "Ainda que por pouco tempo. Ainda que por pouca coisa a ser vista: é preciso cerca de cinco mil vaga-lumes para produzir uma luz equivalente à de 
uma única vela" (DIDI-HUBERMAN, 2011, p.52).

O amor não é possível dentro da cela, dentro do campo, pois a violência reina, mas tal como os vagalumes de Didi-Huberman, que não desapareceram dos céus, ainda existem, devemos apenas olhá-los (Ibidem, p.160), que fecho a passagem ao dizer que, no campo de Schirmeck, "eu me lembro, por exemplo, de dois tchecos, sem dúvida um antigo casal, que conseguiam de vez em quando trocar algumas palavras colocando-se de frente a uma janela do nosso acampamento. Eles se colocavam de costas aos demais e vigiavam pelo reflexo do vidro se alguém surgia" (SELL, 2012, p.53), no que lembra o trabalho audiovisual de Jean Genet, Un chant d'amour (filmado filmado em 1950 na França, mas proibido à época pelo conteúdo explicitamente homossexual, lançado na Dinamarca apenas em 1972), onde há a tentativa de contato entre dois prisioneiros que se desejam, ainda separados por uma parede e observados por um policial, que participa e também está ausente à cena.

Não é preciso o número total de homossexuais europeus deportados durante o confronto na Europa, porém é certo que desse contingente sua grande maioria foi assassinada, mas perceber esses pequenos gestos de amor em meio a barbárie, assim como o testemunho do gesto por meio de relatos como o de Pierre Seel, que sobreviveu e escreveu por si mesmo e também, por que não, para e pelos mortos, assim como ver no relato de Arenas, de "luta e esperança" (ARENAS, 2009, p.377), que dentro da cadeia se utiliza da escrita para endereçar o amor dos encarcerados às suas famílias, por mais que o próprio Arenas ao amor-gozo tenha se exilado em cárcere, que entendemos que por mais que pensemos não ver mais nos céus os vagalumes, como postulou Pasolini, em texto de fevereiro de 1975 (mesmo período em que denunciava a falta de reparo para a deportação e assassínio em massa dos homossexuais na guerra, como aqui já citado), como destaca Didi-Huberman (2011, p.25), por conta do progresso da modernidade (a luz imensa do holofote destruindo a pequena luz do vagalume), ou seja, por mais que pensemos que é impossível um lampejo de esperança e de transmissão da experiência no século em que, aparentemente, a experiência não pode mais ser transmitida, posto que aniquilada pelo algoz (política, cultura), ainda há sim a possibilidade de contar e de viver, pois ainda somos sobreviventes. Quem testemunha, quem conta, o consegue fazer porque não foi destruído completamente, ainda tem a chance de dizer, de contar, de lembrar, de se tocar, de amar. Diz Didi-Huberman:

(As sobrevivências) são lampejos passeando nas trevas, em nenhum caso o acontecimento de uma grande "luz de toda luz". Porque elas nos ensinam que a destruição nunca é absoluta - mesmo que fosse ela contínua -, as sobrevivências nos dispensam justamente da crença de que uma "última" revelação ou uma salvação "final" sejam necessárias à nossa liberdade (Ibidem, p.84, grifos nossos).

\section{MEMÓRIAS DO EU-OUTRO}

Devemos, então, refletir junto a Graciliano Ramos, que afirma sobre os homossexuais presos: 
As minhas conclusões eram na verdade incompletas e movediças. Faltava-me examinar aqueles homens, buscar transpor as barreiras que me separavam deles, vencer este nojo exagerado, sondar-lhes o íntimo, achar lá dentro coisa superior às combinações frias da inteligência (...) Penso assim, tento compreendê-los - e não consigo reprimir o nojo que me inspiram, forte demais. Isto me deixa apreensivo. Será um nojo natural ou imposto? Quem sabe se ele não foi criado artificialmente, com o fim de preservar o homem social, obrigá-lo a fugir de si mesmo? (RAMOS, 1976, vol. I, p.306).

Ele, que não escondeu suas fraquezas e admitiu ter medo, mas reconheceu precisar olhar adiante, enxergar o outro. Ele, também um encarcerado, também uma testemunha, em suas memórias do cárcere, publicada postumamente, em 1953, que contam seu encarceramento entre os anos de 1936 e 1937, devido a questões políticas.

Pasolini novamente pode ser requisitado para nos fazer pensar em torno da problemática do sexo homossexual dentro dos presídios, demonstrado aqui sob diversas formas, seja pelo olhar do heterossexual, seja pelo olhar do homossexual, seja sob coação, seja por escolha. Sendo assim, em texto sob o título La carne in prigione (A carne na prisão), publicado em 1974 em jornal italiano, que posteriormente foi incluído em livro sob o título A prisão e a fraternidade do amor homossexual, Pasolini aborda artigo de um colega que se rebelara contra a notícia veiculada à época de um jovem de quinze anos que, após praticar um roubo, foi encarcerado em um presídio comum, por conta da falta de espaço adequado em uma instituição para menores. Surgiu, portanto, a informação de que ele teria sido coagido a se relacionar com dois presidiários que dividiam com ele a cela, e se rebelado por conta dessa abordagem, sofrendo então uma reação violenta dos outros, e em determinados contextos esses dois presidiários aparecem como dois velhos e em outros como dois menores de idade ou, pelo menos, muito jovens.

A sociedade italiana burguesa se choca, portanto, e de fato, segundo Pasolini, diante da existência do sexo homossexual entre homens dentro do presídio e a possibilidade de homens supostamente heterossexuais estarem praticamente o coito homossexual. De acordo com Pasolini, o natural para a sociedade é a heterossexualidade compulsória, e que se houve a coação sexual do jovem de quinze anos na cadeia, se demonstra que: "o que de fato e em essência ocorreu foi um exercício esquizoide do poder (no caso específico, do poder arcaico e individual da força física) que dissocia o outro de si mesmo e o destitui daquele mínimo essencial de liberdade que é a liberdade do corpo" (PASOLINI, 1990, p.156). No entanto, aborda Pasolini, o "intelectual médio progressista" italiano da época fica pasmo, na verdade, é ao saber da existência do sexo homossexual em cárcere. O crítico destaca que, diante da ideia do sexo homossexual na cadeia, "que é perfeitamente natural", o intelectual médio progressista "sente que está diante do intolerável" (Ibidem, p.159).

Fazer emergir, então, o debate em torno das memórias que durante anos foram silenciadas e apagadas, aqui, no caso, dos homossexuais, não tem por intenção acirrar debates de vitimização e priorizar uma morte mediante outra, vide que tal atitude é, no mínimo, imoral. Deseja-se, isso sim, trazer à luz discursos que não puderam, durante anos, ser ouvidos, em um silêncio muitas vezes cúmplice, que manteve e ainda mantém milhões de 
cidadãos na subalternidade, pela falta de reparação e justiça. O discurso do passado e da memória é vasto e na contemporaneidade absolutamente presente, sendo tanto a falta de memória como seu excesso produtores de distorções. Memórias diversas podem e devem conviver unidas, uma complementando a outra. Como destaca Andreas Huyssen, "dada a nossa cultura contemporânea, encharcada de memória, todas essas diferentes histórias de sofrimento entram em conflito umas com as outras, segundo o modelo 'minha lembrança é mais traumática do que a sua"” (HUYSSEN, 2014, p.183). O autor completa, ao destacar o aspecto de complementaridade e amplitude de perspectivas que memórias podem ter, que

esses diversos campos de memória não apenas se ligam e se sobrepõem, como efetivamente constituem uns aos outros e formam os palimpsestos da memória de nossa época, cada vez mais transnacionais. A vitimação, o sofrimento e a opressão são fenômenos difundidos demais para serem tratados como um jogo de soma zero (Ibidem, p.183-184).

Sendo assim, é importante refletir como determinados enquadramentos de memória moldam nossa reflexão e nos impedem de enxergar esclarecedores aspectos de um evento, que podem estar a nossa frente, apenas não queremos enxergar, ou somos levados a não poder.

\section{REFERÊNCIAS BIBLIOGRÁFICAS E FILMOGRÁFICAS}

ALMENDROS, Néstor; LEAL, Jiménez Orlando. Conducta imprópria. França: TV Antenne 2, 1984;

ANTELME, Robert. A espécie humana. Tradução: Maria de Fátima Oliva do Coutto. Rio de Janeiro: Record, 2013;

ARENAS, Reinaldo. Antes que anoiteça. Tradução: Irène Cubric. Rio de Janeiro: BestBolso, Record, 2009;

. Cartas a Jorge y Margarita Camacho. Edição e notas de Margarita Camacho. Prólogo de Zoé Valdés. Sevilla: Point de Lunettes, 2010;

DIDI-HUBERMAN, Georges. A sobrevivência dos vagalumes. Tradução: Vera Casa Nova e Márcia Arbex. Belo Horizonte: UFMG, 2011;

GENET, Jean. Un chant d’amour. França: 1950;

HUYSSEN, Andreas. Culturas do passado-presente: modernismos, artes visuais, políticas da memória. Tradução: Vera Ribeiro. Rio de Janeiro: Contraponto, MAR, 2014;

LEVI, Primo. É isto um homem? Tradução: Luigi del Re. Rio de Janeiro: Rocco, 1988; 
OLIVARES, Jorge. Becoming Reinaldo Arenas: family, sexuality, and the cuban revolution. Durham and London: Duke University Press, 2013;

PASOLINI, Pier Paolo. Os jovens infelizes: antologia de ensaios corsários. Tradução: Michel Lahud e Maria Betânia Amoroso. São Paulo: Editora Brasiliense, 1990;

POLLAK, Michael. "Memória, esquecimento, silêncio". In: Estudos históricos. Rio de Janeiro: v.2, n.3, p.3-15, 1989;

RAMOS, Graciliano. Memórias do cárcere. $9^{a}$ ed. Rio de Janeiro, São Paulo: Record, Martins, v.1, 1976;

SEEL, Pierre. Eu, Pierre Seel, deportado homossexual. Notas de Jean Le Bitoux e prefácio de Márcio Seligmann-Silva. Tradução: Tiago Elídio. Rio de Janeiro: Cassará, 2012. 
